Gönderilme Tarihi: 14 Eylül 2015

Kabul Alma Tarihi: 10 Aralık 2015

\title{
İŞGÖRENLERİN ALGILAMALARI AÇISINDAN EĞİTİM VE YÜKSEKÖĞRETIM KURUMLARI İLE SINAİ FİRMALARININ FARKLILAŞMASI
}

\author{
Tuna Uslu*
}

öz

Bu çalışma, meslek okulları, üniversite ve sanayi çalışanlarını destekleyen ve güdüleyen etkenler ile algıladıkları bireysel özerklik ve yetkinliklerini Öz Belirleme Kuramı açısından tanımlanmaktadır. Amaç yükseköğretimde ve endüstride çalışanların işlerini yapma, sahiplenme ve performans algı düzeyini etkileyen etkenleri tespit etmektir. Kurama ve araştırmanın modeline göre, iş görenlerin içsel tutum ve davranışları ortaya konulduğunda, ortamsal değişkenlerin doğrudan çıktılar üzerindeki etkilerinin azalacağı düşünülmektedir. Araştırmanın bulguları, algılanan kurumsal destek ve bireysel performans açısından yükseköğretim kurumları ile sınai firmalarının birbirlerinden farklılaştığını göstermektedir. Çalışmada, sektörler arasındaki farkların çalışanlar üzerindeki etkisi de iş nitelikleri, işi sahiplenme ve bireysel performans gibi değişkenlerle kıyaslanmış ve yapı denkliğinde anlamlı farklar bulunmuştur. Sektörlerin kendilerine özgü bu farklarla beraber çalışanların üniversite ve sanayiye farklı bakış açıları, sektörler arasındaki işbirliği imkânlarını da kısıtlamaktadır. Çalışmamızdaki bulgular ışığında, üniversite-sanayi işbirliğine yönelik çözümler de tartışılmıştır.

Anahtar Sözcükler: Kurum Desteği, İş Nitelikleri, İşe Adanmışlık, İşi Sahiplenme, Algılanan Bireysel Performans

\section{THE DIFFERENCES OF VOCATIONAL EDUCATION AND INDUSTRY ACCORDING TO EMPLOYEE PERCEPTION \\ ABSTRACT}

The influences of organizational support, job characteristics and work engagement on psychological ownership and individual performance are related to various theories like Self Determination, Social Identity and Social Exchange Theory. However among theoretical and empirical works for different sectors and groups, there is a shortage of comparing characteristics of higher education and on-the-job training. Besides, due to little study on meta-analytical work, objective results from universities and industry about which variable is influenced by which other one seems hard to find out. The primary objective in this study is to increase the understanding of perceived performance for the higher education and industry by testing relationships between organizational support, psychological ownership and employee attitudes/behaviours. According to proposed model, when the contextual state and organizational behaviors of the employed as mediating variables are presented, the argument is that direct effect of independent variables lessens.

Keywords: Organizational Support, Job Characteristics, Work Engagement, Job Ownership, Perceived Individual Performance

*Gedik Üniversitesi, Meslek Yüksekokulu, İstanbul, E-posta: tunauslu@gmail.com 


\section{Tuna Uslu}

\section{GİRİŞ}

Endüstri toplumu bilim, teknoloji, kitlesel üretim ve ekonomi bileşenlerinin sonucunda ortaya çıkmıştır. Bu süreç 18. yüzyılın sonlarında başlamış, teknolojiler bilime dayalı olarak gelişim göstermiştir. Endüstrileşme ve ekonomik kalkınma da böylece tetiklenmiştir. Üniversiteler bu süreçte bilimsel gelişmenin üreticileri rolünü üstlenirken endüstriler ise teknolojik ve ekonomik büyümenin yaratıcıları olmuştur. Devletin rolü ise özellikle bilimsel çalışmalara parasal destek sağlamaktır. Ancak bu formülasyonda her aktör kendi evrimsel gelişimi içinde yapılanmıştır, bu nedenle ancak üniversite-sanayi işbirliğinde problem gibi görünen temsil ettikleri farklı kültürlerin karşılıklı çıkar ve beklentileri uyumlaştırıldığında optimal sonuç elde edilebilmektedir. Teoride endüstrilere aktarılan doğru bilgi ve teknoloji transferi işletmelerin rekabet gücünü artırmakta, böylelikle yaratılan gelişme ve büyüme üniversitelere aktarılan kaynakları artırmaktadır. Üniversiteler teknolojik gelişime sağladıkları katkıyı eğitime yansıtabildikleri takdirde nitelikli insan gücü yetiştirebilmektedir (Kiper, 2004).

Ancak Türkiye'deki üniversitelerde ve meslek okullarında deneysel ve iş başında eğitim imkanları kısıtııır, diğer taraftan sanayide çalışanlar da pratik uygulamaları kavramsallaştırmaya zaman ve kaynak ayıramamaktadır. Çalışma hayatında da nitelikli eğitim, nitelikli iş dengesi kurulamamaktadır. Bu durum, ekonomik yapılanma ve ulusal iş sisteminden kaynaklandığı kadar, ulusal kültür ve değerlerin de etkisiyle şekillenmektedir. Yapılan araştırmalar, Türkiye'de doğu-batı ikileminin de iş görme anlayışını şekillendirdiğini ortaya koymaktadır (Aldemir, Arbak ve Özmen, 2003). Yerel ve bölgesel kalkınma stratejilerinin düzenleyen kuruluşların da, özellikle kültürel özellikleri dikkate alması gerektiği anlaşılmaktadır (Gülcan ve Aldemir, 2004). Türkiye'de yükseköğretim ve sanayi sektörünün hem iş görme biçimlerinin farklı hem de birbirlerini algılamalarının mesafeli olduğu görülmektedir (Uslu, 2011a). Buradan yola çıkarak, üniversite-sanayi işbirliğinin verimliliğine yönelik bu soruna yerel ve özgün çözümler üretilmesi gerektiği anlaşılmaktadır, bu çözümlerin başında da üniversite ile sanayi arasında ilişkinin yönetim ve organizasyon bakış açısıyla sağlanabilmesi gelmektedir.

\section{İ̧̧ GÖRME ANLAYIŞININ DEĞIŞEN YAPISI}

Yirminci yüzyılda meydana gelen değişimler üzerine oluşturulan yeni bölgesel kalkınma modellerinin dinamiklerini yenilik sistemleri, örtülü bilgi, ekolojik yönetim, örgütsel öğrenme ve öğrenen organizasyon, 


\section{İşgörenlerin Algılamaları Açısından Eğitim ve Yükseköğretim Kurumları ile Sınai Firmalarının Farklılaşması}

araştırma-geliştirme, kültür kuramı ve yönetişim oluşturmaktadır. Bu bağlamda yeni kalkınma politikaları, ulusal yenilik sistemlerinin oluşturulmasına ve uygulamasına büyük önem atfetmekte ve yenilik sürecinde tek bir aktörden ziyade birçok aktörün (üniversite, sanayi, kamu, özel sektör vb.) karşılıklı ilişkisinin önemine ve etkileşimine vurgu yapmaktadır (Niskanen, 2005). Türkiye'de de üniversite ve sanayi işbirliği çerçevesinde, pek çok girişim, proje ve ortak çalışma yapılmasına rağmen bu faaliyetlerin bu sektörlerde çalışanlar tarafından bilinirliliği, sürekliliği ve işleyişe uyumlandırılabilmesi kısıtı kalabilmektedir. $70^{\prime}$ li yıllardan beri Türkiye'de yapılan bu yöndeki çalışmaların ilişkileri ve işbirliğini beklenen ölçüde sağlayamadığı da görülmektedir. Görülmektedir ki, mekanik örgütlenmenin düzenini bozan unsur insan faktörüdür (Aldemir, 1985: 23). Bu nedenle bu süreçte sadece aynı platformda buluşmanın ve altyapı sağlamanın yeterli olmadığı, uygun yöntem ve teknolojilerin içinde bulunulan ortama uyarlanması, örgütsel ve kültürel uyumun da sağlanması ve insan kaynakları yönetiminin gerektiği anlaşımaktadır (Uslu, 2012). İşletmelerin rekabet ortamının iyileştirilmesi ve rekabet gücünün artırılmasında zihinsel süreçlerin geliştirilmesinin ve insan kaynakları yönetiminin büyük önemi vardır. Nitelikli iş gücü ile işletmelerin rekabet avantajı yaratması arasında çok güçlü bir ilişki bulunmaktadır, bu nedenle bölgesel, yöresel ve mikro düzeyde bilgi kazanımı ve yeni insan kaynakları yöntemleri kullanma zorunluluğu ortaya çıkmaktadır (Eryiğit ve Uslu, 2014).

Milli Eğitim Bakanlığı ile Bilim, Sanayi ve Teknoloji Bakanlığı arasında 6 Ekim 2012 tarihinde imzalanan "Organize Sanayi Bölgelerinde Meslekî ve Teknik Eğitimin Güçlendirilmesi" protokolü ile Bakanlıklar ve ilgili Organize Sanayi Bölgeleri Yönetim Kurulu Başkanlıkları işbirliğinde, 15 Temmuz 2010 tarihli ve 27642 sayllı Resmi Gazete'de yayınlanarak yürürlüğe giren "İstihdam ve Mesleki Eğitim İlişkisinin Güçlendirilmesi Eylem Planı"nda yer alan, iş piyasasının ihtiyaçlarına uygun olarak mesleki ve teknik eğitimin verilmesi, eğitim-istihdam ilişkisinin güçlendirilmesi, aktif iş gücü piyasası politikalarının etkin olarak uygulanması, mesleksizlik sorununun giderilerek işgücünün istihdam edilebilirliğinin artırıması hususlarına binaen, bazı organize sanayi bölgelerinde bulunan mesleki eğitim okullarının/kurumlarının kapasitelerinin arttırıması ve yeni özel veya resmi meslek liselerinin kurulmasının hızla yaygınlaştırılması hususunda usul ve esaslar ile tarafların yükümlülükleri tanımlanmıştır. Böylece, organize sanayi bölgeleri hem bir mekân düzenleme aracı, hem 


\section{Tuna Uslu}

bir toplumsal uyumlaştırıcl, hem de bir kalkınma aracı olarak konumlandığı görülmektedir.

Diğer taraftan yapılan araştırmalar, işletme düzeyinde eğitim planlamasına, kadro eğitimlerinin içeriğine, kariyer geliştirme programlarına gerekli önemin verilmediğini ve bu süreçlerin yönetilemediğini göstermektedir (Aldemir, Ataol ve Budak, 1998). Okul ortamında ise, işbaşı eğitimine yönelik veya atölye uygulamaları yarattığı iş yükü ve maliyetler açısından ikinci planda kalmaktadır. Deney atölyesinin düzenlenmesi, eğitim öncesi araç ve gereçlerin yeniden hazırlanması gibi işler nedeniyle maliyetler artmaktadır (Aldemir vd., 2001: 175). Üniversitedeki araştırmacıların sektörel tecrübeleri azdır, sektör çalışanları da pratik uygulamaları kavramsallaştırmaya zaman harcamamaktadır. Bu durumun nedenlerinin başında da, sektörlerin birbirlerini tanımamaları ve kendi geleneksel yapıları içinde işleyişleri gelmektedir. Diğer taraftan, sektörlere özgü meslek standartlarının belirlenmesiyle birlikte, önümüzdeki yıllarda ihtiyaca yönelik olarak eğitim ve gelişim yöntemlerinin özelleşeceği, sektörlere özgün olarak program, yapı ve içeriklerinin farklılaşacağı öngörülebilir. Ancak literatürde özellikle geleneksel yapıların ve sektörel farklılıkların tespitine yönelik araştırmalar oldukça kısıtıdır. Özellikle sanayide çalışanlar üzerinde kurumsal desteğin önemli fiziksel, sosyal ve psikolojik etkileri bulunmaktadır. Bu çalışmada yapılan saha araştırmasında, üniversite ve sanayide çalışanlarının kurum desteği algısı, işlerini sahiplenme ve performans seviyeleri arasındaki farklar, bu farklar sonucu ortaya çıkan sektörlere özgü modeller tespit edilmeye ve kıyaslanmaya çalışılmıştır.

İşletmelerde kurumsal destek, çalışanlar açısından öncelikle finansal destek, daha sonra gelişim imkânları ve kariyer desteği olarak değerlendirilir. Kurumların eğitim ve geliştirme işlevi, çalışanların bireysel ve mesleki gelişimlerinin sağlanması, yeni durumlara uyum sağlamaları, karşılaşılan sorunlara çözüm üretebilmeleri, işletme politikalarını ve akışlarını anlama becerilerinin geliştirilmesi gibi faaliyetleri içerir (Aldemir vd., 2001: 151). Kurumsal desteğin çalışanlar açısından anlam kazanması ve işe yansıması için yönetim ile çalışan arasındaki iletken görevinde olan aracılarla mümkündür. Teknik görevleri olan çalışanlar, idari görevler aldıkça zaman içinde teknik becerilerini kaybedebilmektedir. Diğer taraftan, özellikle teknik işlerden gelen çalışanların, yönetimde görev almadan önce kurum tarafından belirli bir hazırlık aşamasından geçirilmesi ve süreç içinde idari görevlere uyumlandırılması da gerekmektedir (Aldemir vd., 2001: 242). 


\section{İşgörenlerin Algılamaları Açısından Eğitim ve Yükseköğretim Kurumları ile Sınai Firmalarının Farklılaşması}

\section{Kurum Desteğinin Çalışanların İşlerine Etkisi}

Çalışanların desteklenmesi gereken, tüm yetenek ve becerileri ortaya çıkaracak ve örgüt tarafından da desteklenmesini sağlayacak; böylelikle çalışanların kendilerine olan güvenlerini, motivasyonu, örgütsel adanmışlığı artıracak dönüştürücü liderlerin desteği gereklidir. Yüksek kurumsal destek, çalışanlarda etkili çalışma davranışlarını ortaya çıkarır (Watkins, 1995; Naumman, Bies ve Martin, 1995; Malatesta ve Tetrick, 1996). İşletmedeki eğitim fonksiyonu da, çalışanların kişisel ve mesleki gelişimlerinin yanında, örgütsel etkinliğin artırılmasında rol oynar (Aldemir vd., 2001: 167).

Kurum desteği çalışanların olumlu tutum ve davranışları ile, ayrıca bireysel performanslarıyla pozitif ilişkilidir (Ferris ve diğerleri, 1998). Luthans ve arkadaşlarına (2008) göre algılanan kurumsal destek örgütteki pozitif tutumların gelişmesi için ortam sağlar. Kurumunun kendisini desteklediğini düşünen bir çalışan yeni yöntemler denemek konusunda daha ümitli ve girişken bir tavır sergiler. Kurumsal destek algısı, benzer şekilde dayanıklıı̆ı da arttırmaktadır. Kurumun destekleyici tutumu çalışanın iyimser bir yaklaşıma sahip olmasını sağlamaktadır. Kurum çalışanlarının hatasını sadece çalışan kaynaklı değil, aynı zamanda duruma özgü olarak değerlendirerek, çalışanın pozitif bir yaklaşıma sahip olmasını destekler (Luthans ve diğerleri, 2008).

Destekleyici bir kurum, çalışanları ile arasında bağ kurar (Malatesta ve Tetrick, 1996) ve kurumsal desteğin artması çalışanlarda etkili çalışma davranışlarını ortaya çıkarır (Eisenberger ve diğerleri, 1997). Shore ve Wayne (1993) algılanan kurumsal destek ve duygusal bağılıık arasında yüksek korelasyon tespit etmiştir. Algılanan kurumsal destek, çalışanların kendilerini güvende ve kurumlarına sırtlarını dayayabileceklerini hissetmelerine yol açar. Bu sayede çalışanlar, zaman içinde, kurumlarının kendilerini destekleyip desteklemedikleri hakkında genel inanışlar geliştirirler (Eisenberger ve diğerleri, 1990). İşe ve kuruma adanmışlığın öncelleri olarak güçlendirilmiş olma, algılanan kurumsal destek ve işlemsel adalet değişkenlerinin olduğu saptanmıştır (Saks, 2006).

İşletmelerde kurumsal destek çalışanların meslekleriyle özdeşleşmeleri ve işlerini sahiplenmeleri açısından da çok önemli bir rol oynamaktadır. Çalışanlar, yöneticilerin ve kurumun kendilerine değer verdiğini anladığı durumlarda da sahiplenme duygusu geliştirirler (Eisenberger ve arkadaşları, 1990). Algılanan kurum desteği "bu kurum benim kurumum" ve "bu iş benim kendi işim" düşüncesini doğrudan pekiştirmektedir (Uslu, 2011b). Özellikle küçük işletmelerde mesleki 


\section{Tuna Uslu}

özdeşleşme ile işyeri ortamı arasında güçlü bir ilişki bulunmaktadır. Çalışanların mesleki özdeşleşmeleri üzerinde kurum desteğinin ve çalışanların kendi performanslarıyla ilgili olumlu tutumların etkileri pek çok farklı kuramla ilişkilendirilmektedir. Kendine uygun bir işe yerleşen, kurumunun yetki ve sorumluluk verdiği, yönetimin de desteklediği bir çalışanın işine gönülden bağlanması, kendini adaması ve kurumunu sahiplenmesi beklenmelidir.

\section{ARAŞTIRMANIN KURAMSAL ALTYAPISI}

Araştırmanın kuramsal altyapısı Öz Belirleme Kuramı́na dayanmaktadır. Bu kuram üzerine yapılmış çalışmalar, içsel güdüleme türlerinin dışsal olanlara göre başarı üzerinde daha etkili olduğunu göstermektedir. Türkiye'deki sektörler arasında ortaya çıkan kritik ve bağlamsal farklar nedeniyle, sektörlere özgü modeller farklılaşmaktadır (Uslu ve diğerleri, 2011), bu nedenle işbirliğine gidecek sektörlerin her şeyden önce birbirlerinin yapılarını tanımaları gerekmektedir.

Araştırmada kullanılan değişkenler arasındaki ilişkiler, ilgili yazında detaylı olarak incelenmiştir. Bu değişkenlerden işe adanmışlığı (work engagement) çalışanların işlerine kendilerini kaptırmaları ve rol performansları açısından kendilerini fiziksel, bilişsel ve duygusal olarak ifade etmeleri olarak Kahn $(1990,694)$ yeniden tanımlamıştır. İşe ve kuruma adanmışığın bir önceli olarak algılanan örgütsel destek saptanmıştır (Saks, 2006). Ancak işte özerklik de işe adanmışlık üzerinde güçlü bir etkiye sahiptir (Bal, 2008). Görev çeşitliliği, geri bildirim ve kontrol ile çalışanların insiyatif alıp işlerini geliştirmeleri arasında da işe adanmışlık, ara değişken rolü oynamaktadır (Salanova ve Schaufeli, 2008). İşte özerk olmanın, çalışanın bilişsel yetenekleri, iş ile alakalı becerileri üzerinde etkili olarak iş performansını artırdığı ortaya konmuştur (Morgeson ve diğerleri, 2005). Ancak Hackman ve Oldham (1976) iş nitelikleri ile güdüleyici çıktılar arasında bir aşama daha tanımlamıştır. Bu aşamada işin anlamlıı̆ının ve çıktılarının sorumluluğun deneyimlenmesi, sonuçları hakkında bilgi sahibi olma biçiminde üç tutum bulunmaktadır. İş nitelikleri bu kritik tutumlar aracılığıyla çıktılara bağlanmaktadır. Hackman ve Oldham tarafından iş niteliklerinin belli kritik psikolojik tutumlar üzerinden etki ederek duygusal ve güdüleyici çıtıları etkilediği öne sürülmüştür. Çalışanların işlerini sahiplenmesinin, özerklik ile iş doyumu arasında kısmi ara değişken rolü oynadığı tespit edilmiş (Mayhem ve diğerleri, 2007); özerklik, duygusal bağlılık, işi sahiplenme ve iş doyumu arasında pozitif ilişki olduğu gösterilmiştir. Pierce ve arkadaşları da (2009) iş nitelikleri modelini tekrar gözden geçirerek, iş niteliklerini psikolojik 


\section{İşgörenlerin Algılamaları Açısından Eğitim ve Yükseköğretim Kurumları ile Sınai Firmalarının Farklılaşması}

olarak işi sahiplenme ile ilişkilendirmişler ve bu değişken aracilığıyla çıktılara bağlamışlardır.

\section{ARAŞTIRMANIN YÖNTEMİ}

Literatürdeki kuramlar, ampirik bulgular ve fark testleri çerçevesinde eğitim, üretim/imalat, sanayi ve ileri sanayi sektörleri için ayrı ayrı nedensel modeller kurulmuştur, sektörler arasında bulunan anlamlı faklılıklar nedeniyle bu yapısal modellerin de farklıık göstereceği varsayılmaktadır. Bu ilişkiler ışığında aşağıdaki temel model kurulmuştur.

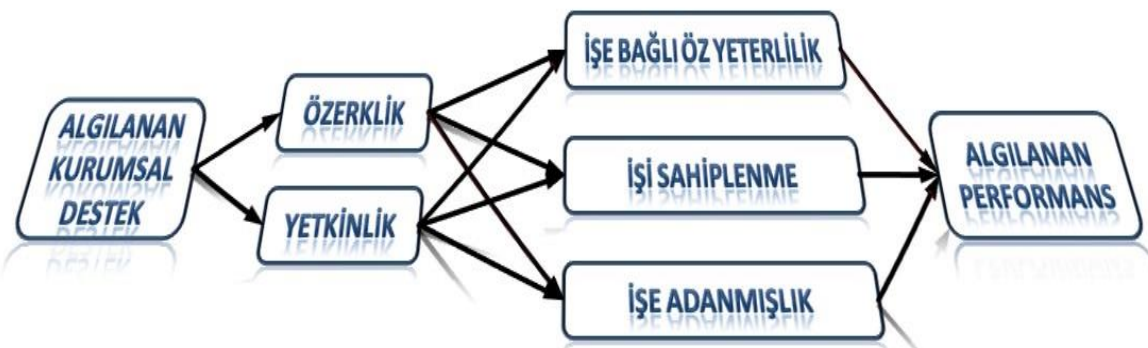

Şekil 1. Araştırmanın Temel Modeli

Çalışmanın amacına yönelik olarak eğitim sektörü ile sınai firmaları arasındaki farklara yönelik hazırlanan hipotezler aşağıda görünmektedir.

H1: Eğitim kurumları ile sınai firmaları arasında, algılanan kurumsal destek açısından fark bulunmaktadır.

H2: Eğitim kurumları ile sınai firmaları arasında, özerklik ve yetkinlik açısından fark bulunmaktadır.

H3: Eğitim kurumları ile sınai firmaları arasında, algılanan bireysel performans açısından fark bulunmaktadır.

Araştırma sorularıyla ilgili verilerin toplanması için kolayda örneklem yöntemiyle eğitim (üniversite, meslek lisesi ve yüksekokulu), üretim/imalat (aydınlatma, gıda, hayvanclık, mobilya, tarım, tekstil), sanayi (ambalaj, ilaç, inşaat, ithalat/ihracat, kimya, makine, otomotiv) ve ileri sanayi (bilgisayar, bilişim, elektronik, enerji, telekomünikasyon) sektörlerinde çalışanlardan 400'ün üzerinde anket toplanmıştır.

Ölçeklerin geçerliği ve güvenilirliğini tespit etmek amacıyla SPSS'de varimax döndürmesi ile keşifsel faktör ve Cronbach Alpha iç tutarlıık analizi uygulanmıştır. Sektör ve çalışanlar arasındaki fark testleri SPPS aracılığıyla, modelin sınanmasına yönelik analizler ve sektörlere özgün ayrı ayrı modeller de AMOS aracılığıyla yapı denklik modeli kurularak test edilmiştir. 


\section{Tuna Uslu}

Araştırmanın Tasarımı ve Ölçekler

Araştırmada kullanılan soru formu iki bölüm, "Demografik Bilgi Formu" ve "Çalışan Durumu Anket Formu" (61 madde) olmak üzere toplam 70 sorudan oluşmaktadır.

"Algılanan Kurum Desteği" Saks'ın (2006) ifadelerine eklenen 8 soru ile ölçülmüştür. "Özerklik" değişkeni için Hackman ve Oldham'ın (1980) ile Breaugh (1985) ölçeklerinden faydalanılmış, "Yetkinlik"için ise Jones'un (1986) ölçeğindeki sorular alınmıştır. "İşe Bağlı Öz Yeterlilik"için Parker'in (1998) öz yeterlilik envanterlerinden faydalanılmıştır. "İşi Sahiplenme" ölçeği için Uslu (2010) kullanılmıştır. "İşe Adanmışık" değişkeni 9 ifadeden oluşan Schaufeli ve arkadaşlarının (2006) Utrecht Engagement Ölçeği'ndeki (UWES-9) orijinal ismi "İs Deneyim Listesi" olarak geçen sorularla ölçülmüştür. "Bireysel İş Performansı'hın ölçülmesinde kullanılan 4 soru Sigler ve Pearson'dan (2000) alınmıştır.

Yanıtlar 1 ila 6 arasında derecelendirilmiş olup 1-hiçbir zaman, 2hemen hemen hiçbir zaman, 3-nadiren, 4-sıklıkla, 5-hemen hemen her zaman, 6-her zaman olarak belirlenmiştir.

\section{BULGULAR}

Toplam 354 katılımcının \%42'si kadın, \%58'i erkek ve ortalama yaş $36,7^{\prime}$ dir. \%53'ü lisans ve \%37'si lisansüstü eğitim düzeyinde olan katıımcıların kurumlarında ortalama çalışma süreleri yaklaşık 8 yı olup, ortalama 15 yıldır çalışma hayatının içindedirler. Çalışmada kullanılan her ölçek ayrı ayrı faktör analizden geçirilmiş ve güvenilirlikleri Cronbach Alpha değerleri ile test edilmiş, güvenilirlik katsayıları 0.70 üzerinde ve kabul edilebilir derecede güvenilir olduğu sonucuna varılmıştır.

\section{Tablo 1. Eğitim Kurumları-Sanayi Ayrımına Göre Algılanan Kurum Desteği}

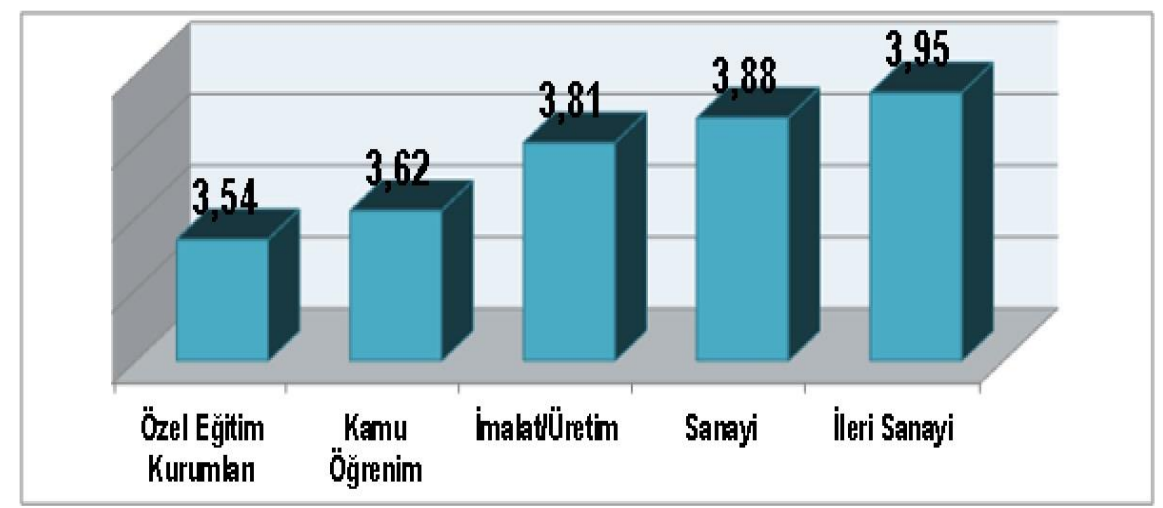




\section{İşgörenlerin Algılamaları Açısından Eğitim ve Yükseköğretim Kurumları ile Sınai Firmalarının Farkıış̧ası}

Üretim bilgi yoğun sektörlere kaydıkça, kurum desteği de artmaktadır. Ancak üniversite ve meslek lisesi çalışanları kurum desteğine sanayiden daha az $(\mathrm{p}<0.05)$ intiyaç duymakta, daha bireysel çalışmaktadırlar, birinci hipotez desteklenmiştir. Özel eğitim kurumlarında, çalışanlar açısından kurumsal destek daha da azdır (Tablo 1).

Eğitim kurumları ile sınai firmaları arasında, özerklik $(p=0.08)$ ve yetkinlik ( $p=0.95)$ açısından anlamlı fark bulunamamıştır.

Sektörlere genel olarak bakıldığında, çalışanların algıladıkları mesleki performansları da sınai firmalarında eğitim kurumlarına göre anlamlı bir şekilde $(p<0.05)$ daha yüksektir (Tablo 2$)$, üçüncü hipotez desteklenmiştir.

Tablo 2. Eğitim Kurumları-Sanayi Ayrımına Göre Bireysel Performans Algısı

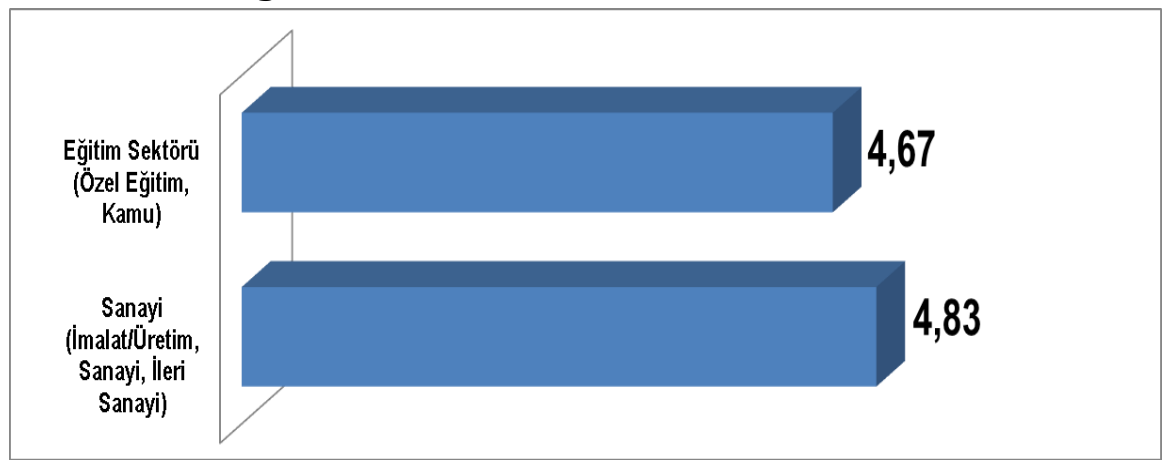

Temel yapı denklik modelimiz (Şekil 1) sınanmış, uyum indeksleri Tablo 3'te verilmiştir. Yazında model uygunluğunun değerlendirilmesi için birden fazla uyum indeksi kullanılmaktadır (Arbuckle ve Wothke, 1999). Bunlardan biri X2 (Ki-kare)'dir. Manidar olmayan X2 değerleri varsayılan modelin elde edilen verilerle uyumlu olduğunu göstermektedir. Yapısal eşitlik modellerinde yaygın olarak kullanılan diğer uyum ölçütleri olan GFI, AGFI, CFI ve NFI değerlerinin de 1'e yaklaştıkça modelin eldeki verilere daha iyi uyum sağladığı anlamına gelmektedir. RMSEA'nın 0,05-0,08 arasındaki değerleri iyi uyumu, 0,05'ten küçük değerleri ise mükemmel uyumu gösterir (Byrne, 1998; Joreskog ve Sörbom, 2001; Teo ve diğerleri, 2003). 


\section{Tuna Uslu}

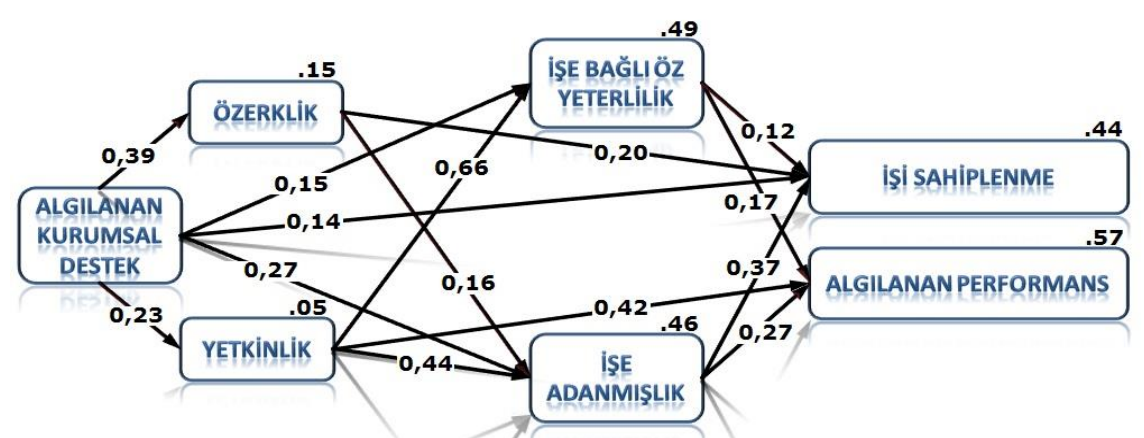

Şekil 2. Eğitim ve Sanayi Temel Modelin İzlek Diyagramı ( $<<$ 0.001)

Araştırmamızdaki modellerin $\mathrm{Ki}$ Kare (X2) değeri manidar olmadığından (Tablo 3) temel modelimiz (Şekil 2) veriler ile uyumludur. Literatürde en çok tercih edilen model uyum ölçütleri dikkate alındığında da, model indeksi toplanan verilerin test edilen modellerle uygun olduğunu göstermektedir. Sonuç olarak eğitim ve sanayi sektörlerine göre farklılaşan (Şekil 3 ve 4) modeller de, indeks bakımından iyi uyum göstermiştir.

Tablo 3. Model Uyum İndeksleri ve Modellere İlişkin Değerler

\begin{tabular}{lccccc}
\hline $\begin{array}{l}\text { Uyum } \\
\text { Testleri }\end{array}$ & $\begin{array}{c}\text { Mükemmel } \\
\text { Uyum }\end{array}$ & $\begin{array}{c}\text { Kabul } \\
\text { Edilebilir } \\
\text { Uyum }\end{array}$ & $\begin{array}{c}\text { Temel } \\
\text { Model } \\
\mathbf{N = 3 5 4}\end{array}$ & $\begin{array}{c}\text { Eğitim } \\
\text { Modeli } \\
\mathbf{N = 1 3 4}\end{array}$ & $\begin{array}{c}\text { Sanayi } \\
\text { Modeli } \\
\mathbf{N = 2 2 0}\end{array}$ \\
\hline GFI & $>0.95$ & $>0.90$ & 0,991 & 0,972 & 0,987 \\
AGFI & $>0.90$ & $>0.85$ & 0,952 & 0,903 & 0,941 \\
RFI & $>0.90$ & $>0.85$ & 0,963 & 0,926 & 0,955 \\
CFI & $>0.97$ & $>0.95$ & 0,995 & 0,985 & 0,995 \\
NFI & $>0.97$ & $>0.95$ & 0,991 & 0,970 & 0,987 \\
RMSEA & $<0.05$ & $<0.08$ & 0,057 & 0,087 & 0,055 \\
(PCLOSE) & & & $(, 343)$ & $(, 171)$ & $(, 383)$ \\
X2 (p) & & $p>0.05$ & 10,720 & 11,978 & 9,944 \\
& & & $(, 057)$ & $(, 062)$ & $(, 127)$ \\
\hline
\end{tabular}

$\mathrm{Bu}$ değerler doğrultusunda oluşan modellerin standart izlek diyagramları da Şekil 3 ve 4'te verilmiştir. Eğitim ve sanayi sektörünün kendine özgü yapı denklik modellerine sahip olduğu, bu nedenle işbirliği girişimlerinin önünde yapısal engeller de olduğu görülmüştür. Temel modelimize göre, artan özerkliğin işi sahiplenme, artan yetkinliğin ise performans üzerinde etkili olduğu görülmektedir. 


\section{İşgörenlerin Algılamaları Açısından Eğitim ve Yükseköğretim Kurumları ile Sınai Firmalarının Farklılaşması}

Eğitim sektöründe, kurum çalışanın sadece işyerindeki özerkliği ve işi sahiplenmesi üzerinde etkili olmaktadır. Öğretim görevlileri, işe adanmaları aracılığıyla kendi içsel yetkinliklerini doğrudan ve dolaylı olarak performans şeklinde ortaya koymaktadırlar (Şekil 3). Eğitim kurumunun desteğine intiyaç duymadan da kendilerini ortaya koyabilmektedirler.

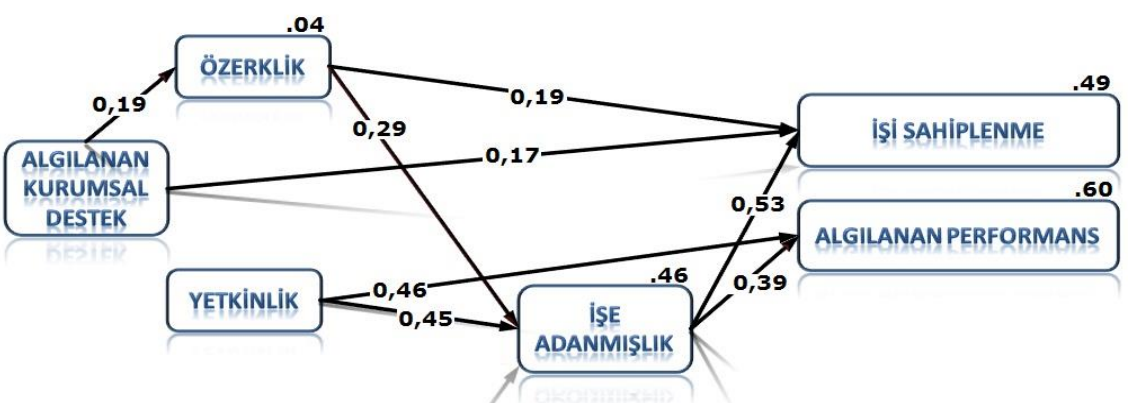

Şekil 3. Eğitim Sektörü Sonuçları $(p<0.01)$

Diğer taraftan, imalat ve sanayi sektörlerinde kurumun desteği özerklik gibi yetkinliğin de bir önceli durumundadır. Sanayi çalışanları, işe bağlı öz yeterlilikleri ve adanmaları aracılığıyla yetkinliklerini doğrudan ve dolaylı olarak performans şeklinde ortaya koyarken, özerklikleri aracılığıyla işlerini sahiplenmektedirler (Şekil 4). Sanayi çalışanları, ancak yaptıkları işle ilintili olarak durumsal öz yeterlilikleri aracılığıyla kendilerini ortaya koyabilmektedirler.

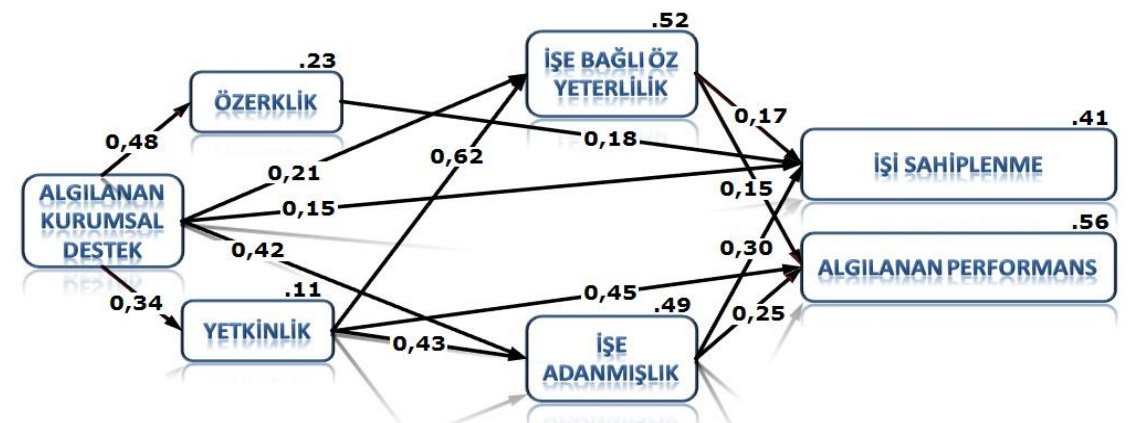

Şekil 4. Sanayi Sonuçları $(p<0.01)$

Bulgularımız, sanayi çalışanlarının işyerlerine bağımlı olduklarını gösterirken, öğretim görevlilerinin kurumlarından bağımsız olarak işlerini algıladıklarını ortaya koymaktadır. Ancak bu tespit bu sektörler arasında 


\section{Tuna Uslu}

kurulacak işbirlikleri açısından da ilginç sonuçları beraberinde getirmektedir.

\section{SONUÇ VE TARTIŞMA}

Sonuçlarımız, sektörler arasında ortaya çıkan çarpıcı farkların, sektörlere özgü bazı kritik ve bağlamsal farklılıklardan kaynaklandığını düşündürmektedir. Görüldüğü gibi, eğitim sektörü çalışanları bağımsız olarak kendi işlerini ortaya koyabilirken sanayi çalışanları ortama bağı olarak emek vermektedirler. Bu çalışmada, sektörlerden bağımsız genel bir modelin yanı sıra ayrı ayrı eğitim ve sanayi sektörlerine özgü modeller ortaya konmuştur. Görülmektedir ki, sektörlerden bağımsız olarak kurulan modelin sektörlere özel açıklayıcılığı kısıtıdır. Bu durum, yapılan ve ileride yapılacak çalışmalarda genel modellerin doğrudan kurama, sektörlerin ayrıştırıldığı modellerin ise daha fazla uygulamaya hitap edebileceğini düşündürmektedir. Sunulan genel modelin sadece veri toplanan sektörlerin gözlemlerinden oluşması nedeniyle genellenebilirliğinin kısıtlı olduğu, diğer taraftan da sektöre özgü farklılıkları da kendi içinde eritmesi nedeniyle sektörlere yönelik de açıklayıcılığının yetersiz olduğu görülmüştür, bu nedenle sektörlere özgü modeller karşılaştırımıştır.

Türkiye'de eğitim ve sanayi sektörünün hem iş yapma biçimlerinin farklı hem de birbirlerini algılamalarının mesafeli olduğu görülmektedir. İşbirliğinin verimliliğine yönelik bu soruna pratik çözümler üretilmesi gereklidir, bu çözümlerin başında da üniversite ile sanayi arasında yapılan ortak çalışmalar gelmektedir. TÜBİTAK, KOSGEB, araştırma konsorsiyumları, danışmanlık hizmetleri, teknoloji geliştirme ve inovasyon bölgeleri, teknoloji ve bilimi ticarileştiren kuruluşlar, teknoparklar, sanayi ve ticaret odaları bu çalışmalarda arabulucu rolü oynamaktadırlar. Aynı zamanda erken yaşta başlayan eğitim stajları, iş başı eğitimleri ve diğer taraftan sanayi kuruluşları tarafından kurulan eğitim kurumları da pratikte işbirliğine hizmet edebilecek girişimler olarak karşımıza çıkmaktadır. Hizmet sektörünün artan rolü de bu aracılığı sağlamaktadır. Ancak bu paydaşların bir programa sağdık kalması ve yönetilmesi de gerekmektedir, aksi takdirde verimsiz süreçlerle tasarruftan çok kaynak ve emek israfı ortaya çıkacaktır. Bu noktada devlet, üniversiteler, sanayi kuruluşları, oda ve borsalar başta olmak üzere tüm paydaşların kendilerini temsil edecekleri ortak bir platformda buluşmaları işbirliğinin öncelidir.

Bu noktadan başlayan sürecin izlenmesi ve yönetilmesi için üniversite-sanayi ortak araştırma merkezlerinin programına uyum, yeteneklerinin geliştirilmesi, ortak çalışmalarda bu merkezlerin söz sahibi olması, sektör intiyaçları doğrultusunda Ar-Ge projeleri tespit etmeleri 


\section{İşgörenlerin Algılamaları Açısından Eğitim ve Yükseköğretim Kurumları ile Sınai Firmalarının Farkıısşması}

gerekmektedir. Ortak katılımlı bu çalışmalarda, ortaya çıkan ürün ve hizmet kadar, süreç boyunca üretilen bilgide kaydedilmeli, geri dönüşüm olarak değerlendirilmeli, paylaşılmalı ve aktarılmalıdır. Bu bilgi işi genişletme ve zenginleştirme uygulamalarında veri olarak değerlendirilmelidir. Farklı endüstrilerde ve eğitim programlarında da farklı kabiliyetlere yönelik yapı ve içerik tasarımına intiyaç vardır (Uslu, 2014). Özel sektör çalışanları daha pragmatik ve esnek bir yapıya sahiptir (Arbak, Aldemir, Özmen, Katrinli, Kesken, ve İshakoğlu, 1997). Sanayi ve özel sektöre yönelik pratik işleyişler, hızlandırılmış süreçler, bilgi transferi ve teşvikli eğitim projeleri, yerel ve bölgesel uygulamalar, yöneticilere yönelik lisansüstü programlar, sahada ve deneysel eğitimler, simülasyon programları, teknoloji ve bilişim sistemlerinin aracılı̆ı̆ıla, okullardaki ders müfredatının ilgili sektörlerle bağlantılı olarak sürekli güncellenen bir dinamik yapı kazanması pratik bir çözüm olarak karşımıza çıkmaktadır. Bu yöntemlerle eğitilenler, doğrudan kendi yapacakları görevleri öğrenmiş olduklarından, bilgilerini işlerine aktarmaları da kolaylaşmaktadır (Aldemir vd., 2001: 175). Özellikle meslek eğitim kurumlarının ve devlet üniversitelerinin bu bilgiyi kendi yeteneklerine eklemeleri ve rekabet avantajı olarak kullanmaları şarttır, aksi takdirde üniversite ve meslek yüksekokulları kendi içlerine dönük ve fikirlerin gelişmesini yavaşlatan bir yük durumuna düşerler. Yeni çalışmaya başlayanlar açısından da, ilk sene sanki okula yeni başlayan bir çocuğun ilk günleri gibi bunalımlı ve belirsiz geçer (Aldemir vd., 2001: 179). Bu nedenle, formal eğitim sürecinin çıktısı olan bu bireylerin endüstride çalışmaya alıştıııması gerekir. Bu alıştırma süreci, okulun son döneminden başlayıp çalışma hayatının ilk senesi boyunca süren programlarla yürütülebilir. Özellikle teknik alanlarda, erken yaşta başlayan eğitim stajları, teknik becerilerin geliştirilmesi, işbaşı eğitimleri ve sanayi kuruluşları tarafından pratiğe yönelik kurulan eğitim kurumları da mesleki gelişime hizmet edebilecek girişimler olarak önerilebilir.

Bu programların devamlılığı ve eğitim ihtiyacına uyumu sağlandığı takdirde, ileriye dönük olarak geliştirilen stratejik planların hedeflerine ulaşmasından ve çalışanların işlerini sahiplenmesinden kaynaklanan verim de artacaktır. Yakalanan verimlilik ve üretilen katma değer aynı zamanda bu ortak girişimlerin, eğitim ve sanayi sektöründe lokomotif rolü oynamasını, zaman içinde bu sektörlerin geleneksel yapılarını da birbirleriyle işbirliğine uyumlu olacak şekilde dönüştürmesini sağlayacaktır. 


\section{Tuna Uslu}

\section{KAYNAKÇA}

Aldemir, C. (1985). Örgütler ve Yönetimi: Makro Bir Yaklaşım, Bilgehan Basımevi; İzmir.

Aldemir, C., Ataol, A. ve G. Budak (1998). Personel Yönetimi, III. Baskı, Barış Yayınları, İzmir.

Aldemir, C., Ataol, A. ve G. Budak (2001). İnsan Kaynakları Yönetimi, IV. Baskı, Fakülteler Kitabevi, Barış Yayınları, İzmir.

Aldemir, C., Arbak Y. ve Ö. Özmen (2003). Türkiye'de İş Görme Anlayışı: Tanımı ve Boyutları, Yönetim Araştırmaları Dergisi, 3(1), 5-28.

Arbak, Y., Aldemir, C., Özmen, Ö., Katrinli, A., Kesken, J. ve G. İshakoğlu (1997). Perceptual Study of Turkish Managers' and Organizations' characteristics: Contrast and Contradictions, Sonja A. Sackman (ed.), Cultural Complexity in Organizations, London: Sage Publications, 87-103.

Arbuckle, J.L. ve W. Woothke (1999). Amos 4.0 User's Guide, SPSS Inc..

Bal, E.A. (2008). Self-efficacy, contextual factors and well-being: the impact of work engagement, Yayımlanmamış Doktora Tezi, Marmara Üniversitesi Sosyal Bilimler Enstitüsü, İstanbul.

Breaugh, J.A. (1985). The measurement of work autonomy, Human Relations, 38, 551-570.

Byrne, B.M (1998). Structural Equation Modeling with LISREL, PRELIS, and SIMPLIS, Lawrence Erbaum Associates Publisher, New Jersey.

Eisenberger, R., Fasolo, P. ve V. Davis-LaMastro (1990). Perceived Organizational Support and Employee Diligence, Commitment and Innovation, Journal of Applied Psychology, 75, 51-59.

Eisenberger, R., Cummings, J., Armeli, S. ve P. Lynch (1997). Perceived Organizational Support, Discretionary treatment and innovation, Journal of Applied Psychology, 82, 812-820.

Eryiğit, N. ve T. Uslu (2014). Uluslararası Teknoloji Transferi ve Bölgesel Kalkınma Çerçevesinde Teknoloji ve Sanayi Kümelenmelerindeki İnsan Kaynağı ve Bilgi Yönetimi, 14. Üretim Araştırmaları Sempozyumu Bildiriler Kitabı, ed. Sıtkı Gözlü, Erkan Bayraktar ve F. Tunç Bozbura, Bahçeşehir Üniversitesi

Ferris, G.R., Arthur, M.M., Berkson, H.M., Kaplan, D.M., Harrell-Cook, G. ve D.D. Frink (1998). Toward a social context theory of human resource management-organizational effectiveness relationship, Human Resource Management Review, 8, 235-264.

Gülcan, Y. Ve C. Aldemir (2004). Bölgesel Kalkınmada Ekonomik Göstergeler İle Yerel Kültür Özellikleri Arasındaki İlişkiler: Aydın ve 
Denizli Örnekleri, Kentsel Ekonomik Araştırmalar Sempozyumu, Cilt I, Mart 2004, Pamukkale Üniversitesi, 220-232

Hackman, J.R. ve G.R. Oldham (1976). Motivation through the design of work: Test of a theory, Organizational Behavior and Human Performance, 16, 250-279.

Hackman, J.R. ve G.R. Oldham (1980). Work Redesign, Addison-Wesley Longman, Inc.

Jones, J.M. (1986). Racism, a cultural analysis of the problem, Prejudice, discrimination and racism, San Diego: Academic Press.

Joreskog, K. ve D. Sörbom (2001). LISREL 8:. User's Reference Guide, Scientific Software International Inc.

Kahn, W.A. (1990). Psychological conditions of personal engagement and disengagement at work, Academy of Management Journal, 33 (4), 692-724.

Kiper, M. (2004). Teknoloji Transfer Mekanizmaları ve Bu Kapsamda Üniversite-Sanayi İşbirliği, Teknoloji, TMMOB 50. Yıl Yayınları, 59122.

Luthans, F., Norman, S.M., Avolio, B.J. ve J.B. Avey (2008). The mediating role of psychological capital in the supportive organizational climate, Journal of Organizational Behavior, 29, 219-238.

Malesta, R.M. ve L.E. Tetrick (1996). Understanding the Dynamics of Organizational and Supervisory Commmitment, Society for Industrial and Organizational Society Annual Meeting, San Diego.

Mayhem, M.G., Ashkanasy, N.M., Bramble, T. ve J. Gardner (2007). A Study of the Antecedents and Consequences of Psychological Ownership in Organizational Settings, The Journal of Social Psychology, 147(5), 477-500.

Morgeson, F.P., Delaney-Klinger, K.A. ve M.A. Hemingway (2005). The importance of job autonomy, cognitive ability, and job-related skill for predicting role breadth and job performance, Journal of Applied Psychology, 9.

Naumman, S.E., Bies, R.J. ve R. Martin (1995). The roles of organizational support and justice during a layoff, Academy of Management Best Papers Proceedings, 89-93

Niskanen, A. (2005). Forest Sector Entrepreneurship in Europe-Summary of Country Studies of COST Action E30, Acta Silv. Lign. Hung. Special Edition, 7-15 


\section{Tuna Uslu}

Parker, S. (1998). Enhancing role-breadth self efficacy: The roles of job enrichment and other organizational interventions, Journal of Applied Psychology, 83, 835-852.

Pierce, J.L., Jusilla, I. ve A. Cummings (2009). Psychological Ownership within the Job Design Context: Revision of the Job Characteristics Model, Journal of Organizational Behavior, 30(4), 477-496.

Saks, A.M. (2006). Antecedents and consequences of employee engagement, Journal of Managerial Psychology, 21(7), 600-619

Salanova, M. ve W.B. Schaufeli (2008). A cross-national study of work engagement as a mediator between job resources and proactive behaviour, The Int. Journal of Human Resource Management, 19(1), 116-131.

Schaufeli, W., Salanova, M. ve A.B. Bakker (2006). The measurement of Work Engagement With A Short Questionnaire: A Cross-National Study, Journal of Educational and Psychological Measurement, 3, 71-92.

Shore, L.M. ve S.J. Wayne (1993). Commitment and employee behavior: Comparison of affective commitment and continuance commitment with perceived organizational support, Journal of Applied Psychology, 78, 774-780.

Sigler, T.H. ve C.M. Pearson (2000). Creating an empowering culture, Journal of Quality Management, 5, 27-52.

Spreitzer, G.M. (1995). Psychological empowerment in the workplace, Academy of Management Journal, 38(5), 1442-1465.

Teo, H.H., Wei, K.K., ve I. Benbasat (2003). Predicting Intention to Adopt Interorganizational Linkages: An Institutional Perspective. MIS Quarterly, 27(1), 19-50.

Uslu, T. (2010). Birey Davranışları Üzerine Bütüncül ve Birleştirici Bir Model Denemesi, International 8th Knowledge, Economy \& Management Congress Proceedings, ISBN: 978-9944-0203-7-4, 1643-1658.

Uslu, T. (2011a) Üniversite-Sanayi İşbirliğinde Kritik Bir Öncel: Sürekli Öğrenme, İşi Sahiplenme, Çalışan Tutumları ve Türkiye'deki Durum Analizi Üzerine Karşılaştırmalı Bir Saha Çalışması, 4. ÜSİMP 4. Kongresi Sonuç Raporu, 2-3 Haziran 2011, 11

Uslu, T. (2011b). Sanayi Sektöründe KOBİ ve Büyük İşletme Çalışanlarının Yatııım Yapma Tercihleri ve İşlerini Sahiplenme Biçimleri, 7. KOBI'ler ve Verimlilik Kongresi Bildiri Kitabı, ed. Müge İşeri, Gülsüm Savcı Gökgöz, İstanbul: İstanbul Kültür Üniversitesi Yayın No: 155, ISBN: 978-605-87976-8-0, 263-270. 
Uslu, T., Çetin, M. ve E.M. Çam (2011). Hizmet Sektöründe Özerklik ve Yetkinlik Algısının İşi Sahiplenme Aracılığıyla Çalışanlara Etkisi: Sağlık, Eğitim ve Turizm Sektörlerinin İnşaat Sektörü İle Karşılaştırıması, 10. Ulusal İşletmecilik Kongresi Genişletilmiş Bildiri Özetleri Kitabı, Dokuz Eylül Üniversitesi İşletme Fakültesi, Kardeşler Cilt Evi, ISBN: 978-975-441-331-1, 427-430.

Uslu, T. (2012) Türkiye'de Üniversite-Sanayi İşbirliğinde Kritik Bir Değişken Olarak İnsan Faktörü, Üniversite Sanayi İşbirliği Merkezleri Platformu-ÜSIMMP 5. Ulusal Kongresi, 21-22 Haziran 2012, Sabancı Üniversitesi, 30.

Uslu, T. (2014). Uzaktan Eğitim Eğilimlerini Yerel Okul ve Üniversitelerin İhtiyaçlarına Uyarlama, XVIII. Türkiye'de İnternet Konferansı Bildiriler Kitabı, ed. Akgül, M. ve diğerleri, 1. Baskı, İnternet Teknolojileri Derneği, Bilgi Kitapevi, ISBN: 978-605-85087-1-2, 141-146

Watkins, A. (1995). Communication Concepts Related to Perceived Organizational Support, Western Journal of Communication, 59(4), 326-347. 